\title{
SI model of measuring the success of strategies and decisions in construction projects using system dynamics
}

\author{
Original \\ Article \\ Ahmed Abd El-Rady Okasha', Amir Arafa', Nabil Amer ${ }^{1}$ \\ ${ }^{1}$ Department of Civil Engineering, Military Technical College, ${ }^{2}$ Administrative Control \\ Authority, Cairo, Egypt
}

\section{Keywords:}

Assess strategyes, success measure, system dynamics.

\section{Corresponding Author:}

Ahmed Abd El-Rady Okasha, Department of Civil Engineering, Military Technical College, Cairo, Egypt, Tel: 01005498450

Email: ahmed.okasha@mtc.edu.eg

\begin{abstract}
This paper uses system dynamics (SD) approach to predict and measure construction projects strategies and decisions success. SD model captures construction projects design phase processes using VENSIM software to simulate policies used. The model is validated by comparing results for the base case of Love, Edwards et al. 2008 model. Two scenarios are proposed to overcome owner changes. These changes are minimizing project schedule from 45 to 25 weeks. Polices used to overcome these changes are: 1 - assign overtime to the available designers to increase the work output (one designer work more than one shift); 2- assign more experienced designers to work without assigning overtime to these designers (increase the available designers but the designer work only one shift). The SI model is developed to compare between these two scenarios. Two-round Delphi questionnaire are used for data gathering to build structure index (SI) model that represent measure of project success. Four success parameters; time, cost, quality, and Client's Satisfaction; are used to formulate a success measure index for construction projects. This helps in indexing the success of finished projects in order to compare with each other. Also, using the proposed SI model with SD helps in measuring organization strategy success. And, help decision makers to assess their decisions. The results show that more designers assigned to finish the work in time (i.e. scenario two) is better than scenario one (i.e. better than working overtime that leads to more rework and increases the cost).
\end{abstract}

\section{INTRODUCTION}

Nowadays, complexity is one of the key components of mega construction projects; typically they are "largescale, complex ventures, cost a billion dollars or more, take many years to develop and build, involve multiple public and private stakeholders, are transformational, and impact millions of people"[1]. It plays a crucial role in the project life cycle ${ }^{[2-4]}$. However, the debate continues about the best management method in construction projects management, either traditional methods or system dynamics (SD) approach $^{[5]}$. Recently, SD approach surpasses the traditional methods in dealing with complexity of construction projects $^{[6]}$. My interest in this area developed because of its important role in the strategic management, which is the compass of the organization. In addition, my interest increased after reading many researches assure that, SD enables capturing the complexity of mega projects, feedback relations, and having the ability to model future strategies of the organization ${ }^{[7]}$. Also, it links project components, stakeholders, and other subsystems which describe the construction project as a holistic system i.e. system of systems. Finally, system's perspective of dynamic planning and control methodology to support the strategic and operational aspects of project management requires $\mathrm{SD}$ as a main approach ${ }^{[8]}$. It is now well established that SD is effectively examines strategies and policies. However, Much less still exists about the relationship between SD and its integration with other techniques ${ }^{[9]}$. It could be used with the Delphi questionnaire to support it with the structure index (SI) model to evaluate strategies, policies, and scenarios according to it.

A considerable amount of literature has shown that project success measures have been changed over years. The triangle of time, cost and quality considered the basic measures of project success. In addition, the soft measures or subjective measures such as stakeholder's satisfaction; and safety are issues that considered in the construction industry. Literature shows variations of success measures. They are considered at both delivery and after delivery 
stages ${ }^{[10]}$. In addition, they are viewed from the macro and micro points of view ${ }^{[1]}$. Also, there are different perspectives $^{[12-16]}$.

However, the previous published studies are limited to local surveys ${ }^{[11,14,17-19]}$; the main purpose of this paper is to investigate the factors of measuring performance for mega complex construction projectsin Cairo, Egypt. And model a SIto measure the success at the strategic levelby means of Delphi questionnaire and survey."The survey done in Cairo, Egypt because Cairo is the capital and have wide range of available and highly qualified experts,I mean that meetings held on Cairo, Egypt".

This questionnaire and survey specify the parameter of measuring the performance index of the strategy used. This success measurehas been modeled in a SI model and has been validated using another questionnaire. The majority of surveyed experts agreed that the proposed model can be applied effectively. This model is applicable to the forms of construction projects e.g. roads, railways, etc.Then, integrate this SI model with system dynamic model.It's worth to mention that, SD model is built for the design phase of construction projects using VENSIM software. And validated by comparing results for the base case of Love, Edwards et al. 2008 model.

The main scope and objective of this research is to build simple model using system dynamic approach that help in the assessment of strategies and decisions taken by decision makers.Hence, this work will generate fresh insight into assessing the decisions and strategies by decision makers using system dynamics modelling. Therefore, this study makes a major contribution to research on assessing and comparing the current and future projects' strategy and organization vision. In addition, it enables measuring current project performance and the dynamic performance of organizations. It's worth to mention that SI and SD models are integrated for the same goal. i.e. SD model captures the feedback loops and the relations between project variables, while the SI model evaluating the process and the results out of the simulation. In other words, SI model privileges a quantitative base to measure the behavior arise from simulation.

The structure of this paper is as follow; first, develop SI model using two round Delphi survey and a questionnaire to validate the model; second, modeling the design phase of construction projects using system dynamics methodology; third, simulate two scenarios to overcome changes done by owner; finally, apply SI model to evaluate the two scenarios to help decision makers in strategic planning and taking decisions.

\section{METHODOLOGY OF RESEARCH}

First, SD used to simulate design phase of construction projects. Following, the criteria of measures is quantified using a two-round structured questionnairewith 23 experts (respondents profile is presented in Table 3). In the first round of the survey, definitions of ten success measures shown in table 1, experts were asked to comment on the measures and quantify there agreement on Likert scale from 1 to 5, where 1: strongly disagree, 2: disagree, 3: neutral, 4: agree and 5: strongly agree. Their comments in the first round recommended first, using Time performance index as a measure rather than the two criteria Time and Schedule, second, using Cost performance index to measure how the expenses or cost relate to the budget rather than using the two criteria cost and budget, finally use Client satisfaction index to measure the expectation and satisfaction of client. Hence, the ten criteria are compromised to be seven criteria. In second round, results from first round were provided to experts and then they scored the seven edited measures as in table 2 with the average score of metrics for different round questionnaire. Considering expert comments, the questionnaire is edited and the second round is initiated. In this round participant experts recommended that:regarding this measure is for future prediction of strategy performance, it's better to consider strategy safe and make the function of project either it will not be applicable on the real cases. Hence, these two criteria are excluded from the measure. On one hand, administration burden consists of multiple dimensions that interact with each other, most of them depend on the government regulations and law, and the others depend on the company. On the other hand, the introduced model is looking forward to deal with measuring the efficiency of policies used in facing problems of design and construction phases without detailing in the administrative process. So, their final recommendation is to exclude the administration burden out of survey scope. At the end the four most rated measures are selected: Time Performance, Quality Performance, Cost Performance, and Client Satisfaction.

Table 1: Common Criteria in Previous Research ${ }^{[20]}$

\begin{tabular}{lc}
\hline Metrics & Definitions \\
\hline $\begin{array}{l}\text { Budget } \\
\text { Cost }\end{array}$ & $\begin{array}{c}\text { Planned value of project cost. } \\
\text { Actual cash paid. }\end{array}$ \\
Time & $\begin{array}{c}\text { The project's construction speed, } \\
\text { delivery speed and schedule growth. } \\
\text { Quality }\end{array}$ \\
Tatisfaction accepted standard. \\
Functionality & $\begin{array}{c}\text { Expectations of end-user are met. } \\
\text { Work properly according to } \\
\text { technical standard. }\end{array}$ \\
Schedule & $\begin{array}{c}\text { The planned contracted time. } \\
\text { The warranty standard. }\end{array}$ \\
Safety & $\begin{array}{c}\text { The construction process does } \\
\text { not unduly burden the owner's } \\
\text { project management staff. }\end{array}$ \\
Administration & $\begin{array}{c}\text { Relative comparison of owner } \\
\text { expectations from project concept as } \\
\text { compared to the completed project. } \\
\text { Relative comparison of owner } \\
\text { burden }\end{array}$ \\
expectations from project concept as \\
compared to the completed project.
\end{tabular}




\section{II.I. SELECTION OF EXPERT PANEL}

Respondents for this study are selected from a range of professionals engaged in the Egyptian construction sector. And, they were identified through recommendation by other experts. The validity of the survey is based on the panel of experts.All the respondents identified for this study had experience on relatively large construction projects in Egypt. Table 3 provides the descriptive statistics of the respondents' profiles in terms of their professional roles and experience in the industry. In order to seek the best possible response for this study, introductory conversations were made with each respondent to explain the objectives of the research. As mentioned in table 3 the respondents are construction, roads, and project management experts.

The main purpose of considering these categories of experts that is major mega projects held in recent years in Egypt are in both Construction and Roads. In addition, project manager have a good knowledge of other categories of projects. i.e. their conclusion is based on their whole knowledge and experience not only on their specific category. So, the model could be applied to other Construction projects. In addition,the mentioned project management experts have experience in different fields related to construction industry as financial services, law (construction contracts and litigations), and information technology i.e. they are not experienced in the field of road or construction. Their experience is range from more than 10 years to more than 20 years. Also, they are engineers, instructors, assistant professor, and professors. In addition they all work in public sector. Finally, all the respondents were actively involved in medium to large sized construction projects.

However, the sample size is relatively small; the quality of the responses was considered highly reliable for the analysis because of the respondents'relevant industry experience, personal interactions and clear understanding of the questionnaire.

The experts selected represent a wide range of professionals in Egyptian construction sector and provide a balanced view for the Delphi study.

Table 2: Average Score of Metrics

\begin{tabular}{lcc}
\hline Metrics & First round & Second round \\
\hline Time & 4.08 & 4.30 \\
Quality & 4.01 & 4.15 \\
Cost & 3.93 & 4.06 \\
Satisfaction & 4.52 & 3.98 \\
Safety & 3.98 & 3.57 \\
Functionality & 3.82 & 3.62 \\
Administration burden & 3.80 & 3.94 \\
Schedule & 3.92 & \\
Budget & 3.75 & \\
Expectation & 3.68 & \\
\hline
\end{tabular}

Table 3: Respondents Profile

\begin{tabular}{|c|c|c|c|c|}
\hline \multicolumn{2}{|c|}{ Field of work } & \multirow{2}{*}{$\frac{\text { Construction }}{4}$} & \multirow{2}{*}{$\frac{\text { Road }}{4}$} & \multirow{2}{*}{$\frac{\text { Project Managemen }}{2}$} \\
\hline & $10-20$ & & & \\
\hline LAperitite (ycais) & $>20$ & 6 & 3 & 4 \\
\hline & Engineer & 2 & 1 & 2 \\
\hline & Instructor & 3 & 3 & 3 \\
\hline \multicolumn{5}{|l|}{ Role of Profession } \\
\hline & Assistant Professor & 3 & 2 & 1 \\
\hline & professor & 2 & 1 & - \\
\hline Total in each categor & & 10 & 7 & 6 \\
\hline
\end{tabular}




\section{II.II SURVEY RESULTS}

As mentioned above, the first set questionnaire aimed to measure the success criteria. Consequently after the first round, 7 project success criteria were suggested by the panel of experts. Following that the second round is launched resulting in 4 project success criteria were suggested by the panel of experts to be: Time Performance, Quality Performance, Cost Performance, and Client Satisfaction. Finally, experts were asked whether they would like to reassess their first score on the same fivepoint Likert scale for these 4 criteria. Simple statistical analysis was conducted using a Statistical Package for the Social Sciences called (MINITAB). The first set of analysescalculates the Mean Rank in order to sorting the success measures. Another significant aspect is the concordance among the panel of experts with respect to their rankings of the project success measures;as a result of this Kendall's Coefficient of Concordance was used. Kendall'sCoefficient of Concordance ranges from zero to one, the higher the value the more the concordance, it's calculated as follow:

$$
W=\frac{12 \sum D^{2}}{m^{2}(N)\left(N^{2}-1\right)}
$$

Where:

W: Coefficient of concordance

D: Difference between the individual sum of ranks of the experts and the average of the sum of ranks

$\sum \mathrm{D}^{2}:$ is the sum of the square differences m: number of experts

$\mathrm{N}$ : number of success measures

$$
W=\frac{12 * 4669.74}{\left(23^{2}\right)(10)\left(10^{2}-1\right)}=0.107
$$

Let us now considerif there is harmony among the ranking of the measures.

Hypotheses:

- Null hypothesis: H0: There is no harmony in the ranking. - Alternative hypothesis: H1: There is a harmony in ranking.

Where the value of $w$ is very large for the Kendal critical value tables, then rounding the chi-square for the distribution of the samples is calculated as follows:

$$
\mathrm{X}^{2}=\mathrm{m}(\mathrm{n}-1) \mathrm{W}
$$

$\mathrm{X} 2=23 * 9 * 0.107=22.149$

Level of significance:

$\alpha=0.05$

df $($ degree of freedom $)=23$

$\mathrm{N}=10$

The $P$ value computed using EXCELL function CHISQ.DIST.RT; hence value $=0.0084<0.05$ ok

Since computed $P$ value is less than alpha, thus null hypothesis $\mathrm{H}_{0}$ is discarded and $\mathrm{H}_{1}$ is accepted.

Hence, there is a harmonyin the expertsresponses. Moving on now to considerweight factor, its definition has evolved from a questionnaire distributed to 50 people (consultants, engineers, and project managers). The profile of respondents is shown in table 4.

Table 4: Respondents Profile for the 50 Experts.

\begin{tabular}{l|ccc}
\hline \multirow{2}{*}{ Experience (years) } & \multicolumn{3}{c}{ Field of work } \\
\cline { 2 - 4 } & Construction & Road & Project Management \\
Role of Profession & 5 & 4 & 3 \\
& 8 & 6 & 3 \\
Total in each category & 7 & 17 & 7 \\
\hline
\end{tabular}

The profile of the panel of experts consists from 50 experts has the same field experience the first 23 expert but differ in years of experience and number of experts. It's worth to mention that after the size of expert panel doubled (from 23 to 50), there was a significant difference between the two conditions, thecost and quality performances rank differs but they become almost near from a same point. This confusion doesn`t mean that the 23 expert perception differ from the 50 expert perception, but this means after enlarging the size of expert panel the more accurate result we get. By research, authors and researchers recommend 10 practitioners for each criterion, though for the four criteria, 50 practitioners are enough. And by confidence level 0.05 or 0.95 with precision $8 \%$ the sample size is 28

Sample Size - Infinite Population (where the population is greater than 50,000 ) 


$$
\mathrm{ss}=\frac{\mathrm{z}^{2} * \mathrm{p} *(1-\mathrm{p})}{\mathrm{c}^{2}}
$$

$\mathrm{SS}=$ Sample Size $\mathrm{Z}=\mathrm{Z}$-value A (e.g., 1.96 for a 95 percent confidence level) $\mathrm{P}=$ Percentage of population picking a choice, expressed as decimal $\mathrm{B} \mathrm{C}=$ Confidence interval, expressed as decimal (e.g., .04 $=+/$ - 4 percentage points) A Z-values (Cumulative Normal Probability Table) represent the probability that a sample will fall within a certain distribution. The $\mathrm{Z}$-values for confidence levels are: $1.645=90$ percent confidence level $1.96=95$ percent confidence level $2.576=99$ percent confidence level).

As previously stated, the respondents representedtheir response by giving a number between 0 (not important) to 10 (very important). By using MINITABE software, the calculated weight factors are calculated and presented in Table 5.

Table 5: Weight factors for the final project success measures

\begin{tabular}{lcc}
\hline Project Success Measures & Mean Rank & Corresponding Weighting \\
\hline 1 Time Performance & 3.28125 & 0.328 \\
2 Cost Performance & 2.50694 & 0.250 \\
3 Quality Performance & 2.38889 & 0.238 \\
4 Client Satisfaction & 1.82292 & 0.182 \\
\hline
\end{tabular}

\section{II.III. Proposed strucred index model}

The structured index model will be calculated by using the following equation:

$$
\mathrm{SI}=0.328 \mathrm{TP}+0.250 \mathrm{CP}+0.238 \mathrm{QP}+0.182 \mathrm{CS}
$$

Where:

- SI: Success Index

- TP: Time performance

- CP: Cost performance

- QP: Quality performance

- CS: Client's Satisfaction

Interestingly, this formula is a general indicator of performance that focuses on critical aspects of outcomes. Also, it's a simple formula while having a complex one can be time and resource consuming. In addition, data collected for using this formula are simple. Moreover,the measures are accepted by experts to be effective measure of performance. And, it could be easily updated.

The validation of SI model is based mainly on the panel of experts opinion which is the core of Delphi method validation $^{[21]}$. In addition, reliability analysis is done on the results of these questionnaires.

\section{II.IV. Model verification}

To assess model verification a questionnaire has been designed to investigate the opinions of experts in the construction field about the proposed model applicability and practicality. Therefore, the questionnaire was designed with a scale from 1 to 4 . Following that, it was distributed through a structured sample of experts in this field. The questionnaire was designed to verify the following:

- The efficiency of the proposed elements in measuring performance in Egyptian construction companies,

- The practicality of measuring them as well.

Responses from professionals were collected and analyzed using (MINITAB) software. Further analysis showed that that:

$1-80 \%$ of respondents found the elements of the model fair enough to measure the performance of the construction companies. This is based on the mean score of 3.0930 and median of 3.1500 in a scale from 1 to 4 , which are considerably positive reactions.

2 - In their response to the efficiency of suggested indicators, the mean scores the mean score of 2.980 and median of 3.0900 , which indicates an agreement among the majority that the indicators of each element are sufficient enough to measure that element and consequently the model is reliable for measuring the performance of construction projects in Egypt.

The above mentioned results insure that the selected indicators for model's elements are sufficient and practical for measuring the performance of construction firms in Egypt.

\section{II.V. Reliability Analysis}

The reliability coefficient Cronbach's alpha $(\propto)$ is calculated 0.872 .Thismeans that the scale is reliable. In addition, $(\propto)$ was calculated to the indicators as well.The results reflect their importance in measuring performance in construction firms and indicate that the scale is reliable.

\section{SD MODEL BUILDING}

With regard to literature and by refinement of Love model ${ }^{[22]}$, Lyneis model ${ }^{[6]}$, and Rodrigues model ${ }^{[23]}$, SD model is built. It consists of five subsystems: Human resource subsystem; Productivity subsystem; Quality subsystem; Work flow subsystem; adverse dynamics (counter actions) subsystem. These subsystems are discussed in the following sections. 


\section{III.I. Human Resource Subsystem}

Human resources are the main power of projects. By means of work force, the design of drawings is executed. Also, it controls the productivity of project and the quality of work done too. Figure 2 shows the human resource subsystem. While, designers of project may be hired as "New Designers", and then trained.Or/and may be inducted from other projects within the organization as "Inducted Designers", who are not requiring training. This is because they already trained at first time they were hired to the organization. Both inducted and trained Designers are accumulated in "Experienced Designers" pool. Designers from this pool are executing the required drawings. "Experienced Designers" contribute to the decline or increase of the productivity. Productivity within this model refers to the rate at which drawings are deigned. Designers' skills, Designers' availability, overtime, supervision, management system, fatigue, moral, and training are all factors play a role indeterminingthe productivity

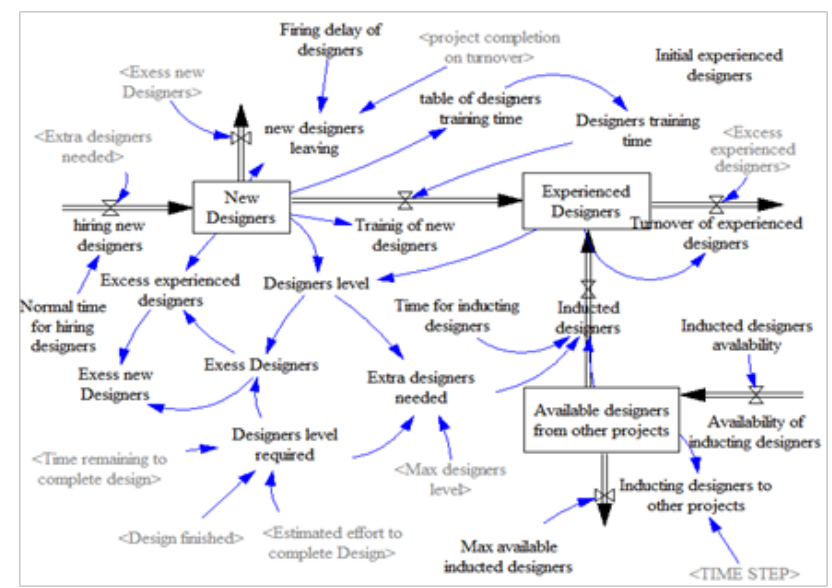

Fig. 1: Designers collection cycle [adopted from [6, 22, 23]]

Productivity is computed from the following equation:

$$
P=\operatorname{Mean}\left(F_{p l}, M_{p l}, L_{p l}\right) * M i n\left(\frac{W_{l}}{T_{n w}}, P_{n l} * L_{e x}\right)
$$

Where:

P: Productivity of doing tasks.

$\mathrm{F}_{\mathrm{pl}}$ : Effect of fatigue on productivity of Designers.

$\mathrm{M}_{\mathrm{pl}}$ : Effect of managerial gap on productivity of Designers.

$\mathrm{L}_{\mathrm{pl}}$ : Learning effect on productivity of Designers.

$\mathrm{W}_{1}$ : Design load.

$\mathrm{T}_{\mathrm{nw}}$ : Normal time for design drawings required.

$\mathrm{P}_{\mathrm{nl}}$ : Normal productivity.

$\mathrm{L}_{\mathrm{ex}}$ : Experienced Designers.

The key factors, as mentioned in Eq. (5), contribute to the productivity of project. The productivity is not a fixed number entire the project; it represented in the model by a random variable within acceptable limits. These limits are the minimum and maximum productivity could be achieved.
In addition to the productivity, "Experienced Designers" affects quality too.In general,quality is conformance to established requirement. In this model, it is the percentage of conformance of design done by designers (i.e. the percentage of drawings designed correctly). The more the quality, the less errors generated (i.e. less rework), and the more customer satisfaction. Many factors such as standard used (required quality), market conditions (i.e. normal quality of Designers), and management system used are responsible for the quality of design. Equation (6) illustrates how the model calculates it.

$$
Q=Q_{n}^{*} \operatorname{Mean}\left(F_{q}, C_{q}, M, S\right)
$$

Where;

Q: Quality of Design.

$\mathrm{Q}_{\mathrm{n}}$ : Normal quality of Designers.

$F_{q}$ : Effect of fatigue on quality.

$\mathrm{C}_{\mathrm{f}}^{\mathrm{q}}$ : Effect of communication on quality.

$\mathrm{M}_{\mathrm{f}}$ : Effect of managerial gap on quality.

S: Effect of Stress on quality.

Quality is like productivity as it represented in the model by a random variable within acceptable limits. These limits are the minimum and maximum quality could be achieved. In the following section it will be shown how quality splits the work into correct category and defective category.

\section{III.II. Work Flow Subsystem}

The work flow of project is based on the rework cycle which is the core of the model. Figure (2) representing this cycle. Starting from the "Required Design Load", this is the initial value of the "Design required". It performed by the "Designers productivity" and is calculated by Eq. (5). Then, "Quality" splits work into two categories "Design done" and "Design with Errors".

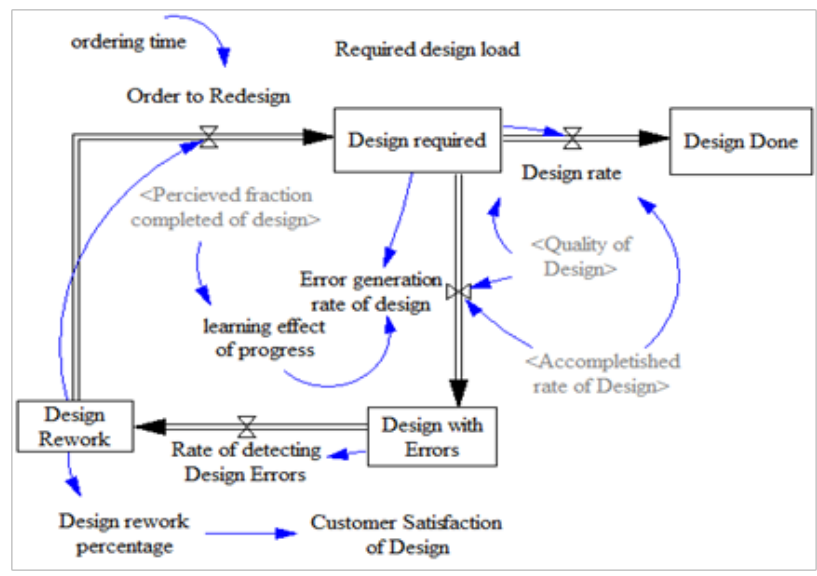

Fig. 2: Design reworks cycle [adopted from [6, 22, 23]]

The "Design done" is the amount of design done correctly either from the first time or after reworked. As provided in Figure (2)the "Accomplished rate of Design" is the responsible for the "Design done". Following that, 
the "Design with Errors", which is the portion of work not done correctly from first time. Consequently, errors generated by "Error generation rate of design", which influenced by many factors, not mentioned in Figure (2). As a consequence of delay in detecting errors generated,it generatesmore hidden rework. Time of detecting these errors is depending on the management system used i.e. if the management system is powerful then the time required to discover the errors is small. After detecting these errors it s called "Design Rework" and are waiting for the order to be redone again. The time taken for reordering this rework is assumed to be the same as detecting time. This rework extends project duration. Finally, the rework is redone again by the Designers and may have errors again then take the same cycle in redoing it.Project manageruses counter actions to close the gap between planned and actual performance. There are four alternatives for counter actions represented in this model: Overtime, Hiring new employees, Extending completion date, and reducing requirements.

\section{SIMULATION PARAMETERS}

The structural validation of the model was conducted. In addition, the model is tested for behavior prediction by usingparameters value of Love et. al. model ${ }^{[24]}$ and comparing the results. The simulation parameters are:

- Work to be done: 200 Drawings.

- Planned scheduled: 45 Weeks, dt=0.25.

- Initial available Designers: 5 Designers.

- Base case $(\cos \mathrm{t}=3000000 \$)$ - simulation is for Design the required drawings without changes.

- Case 1,2 are for projects with change in completion time to be 25 weeks instead of 45 weeks.

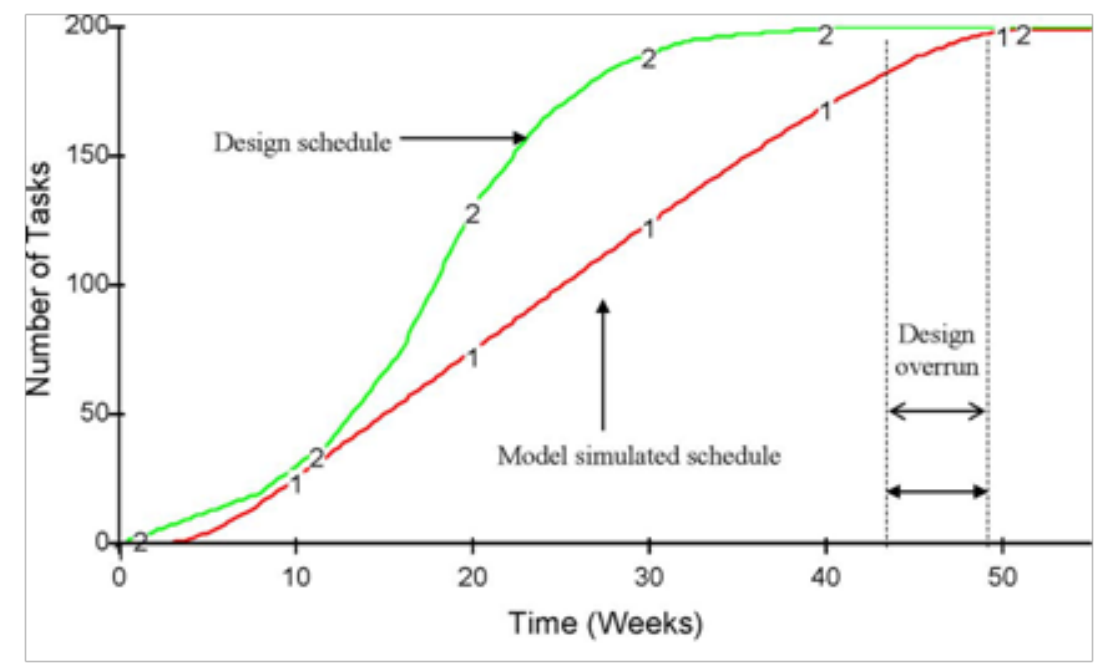

Fig. 3: Project work flow[24]

\section{Design Done}

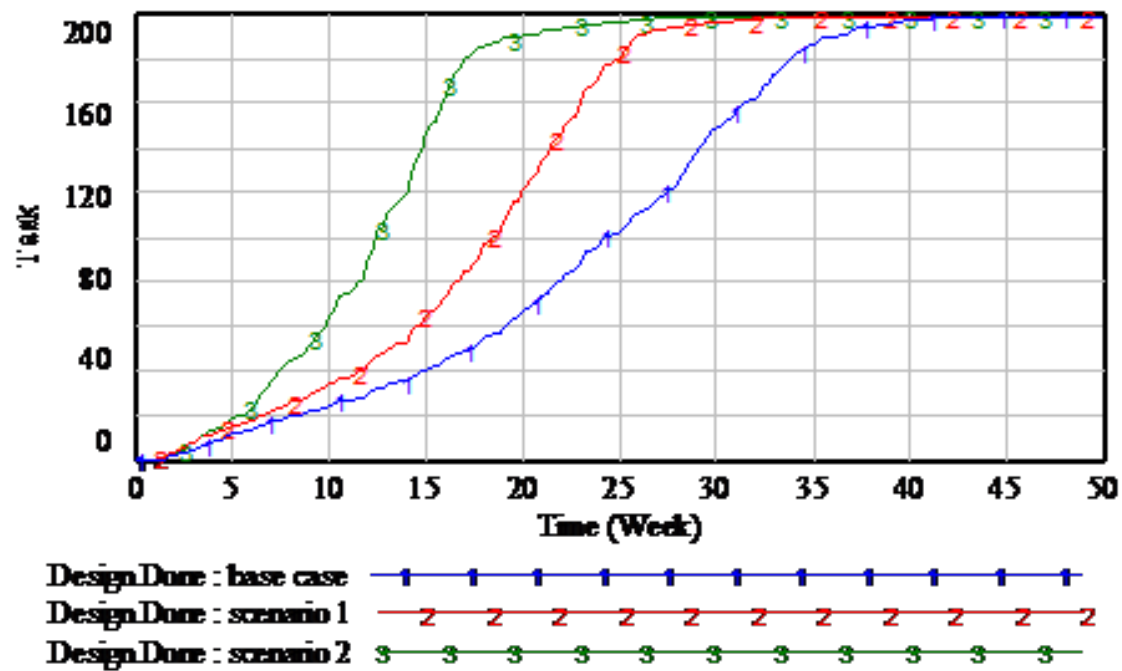

Fig. 4: Design done by simulation of this mentioned model 


\section{IV.I. Base Case:}

Figure (4) represents the number of Drawings i.e. Tasks Done with respect to time for the three cases solved by the model. Both results from the two models are the same for the base case. Wherever, $100 \%$ of work completed at 45 weeks from Love et. al. model ${ }^{[24]}$, also it is finished at 45 weeks for this model as shown in Figure (3) and Figure (4). Figure (4) presents a significant difference in completion time for the other two scenarios that will be discussed in the next sections. By extracting the values of indices from the simulation of SD model, it's found that PSI is $89.089 \%$. This is compared with other scenarios in table (6).

Total Reowk in Design

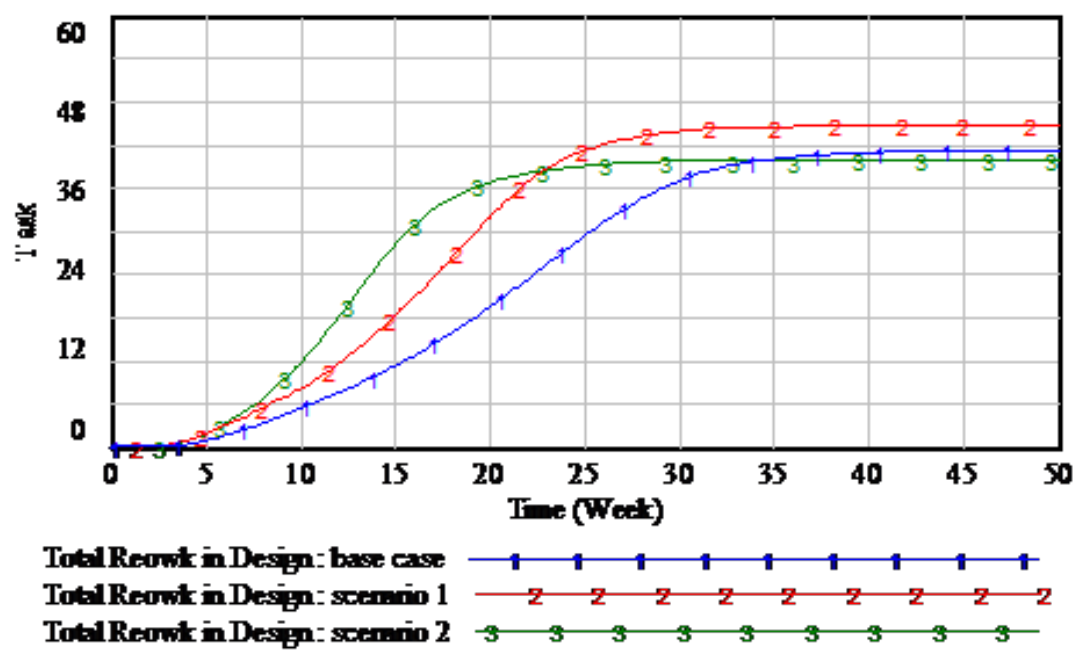

Fig. 5: Total rework in the design process

Figure (6) represents the total estimated cost of the project according to the applied strategy. That indicatessignificant increase in the total number of the estimated cost for every different strategy from the base case. These changes is representing the impact of rework (as in Figure (5)), the number of designers (as Figure (7)), and other aspects contributing to this change according to the strategy tested as mentioned above. In the next section the second strategy of increasing the resources i.e. the number of designers will be tested.
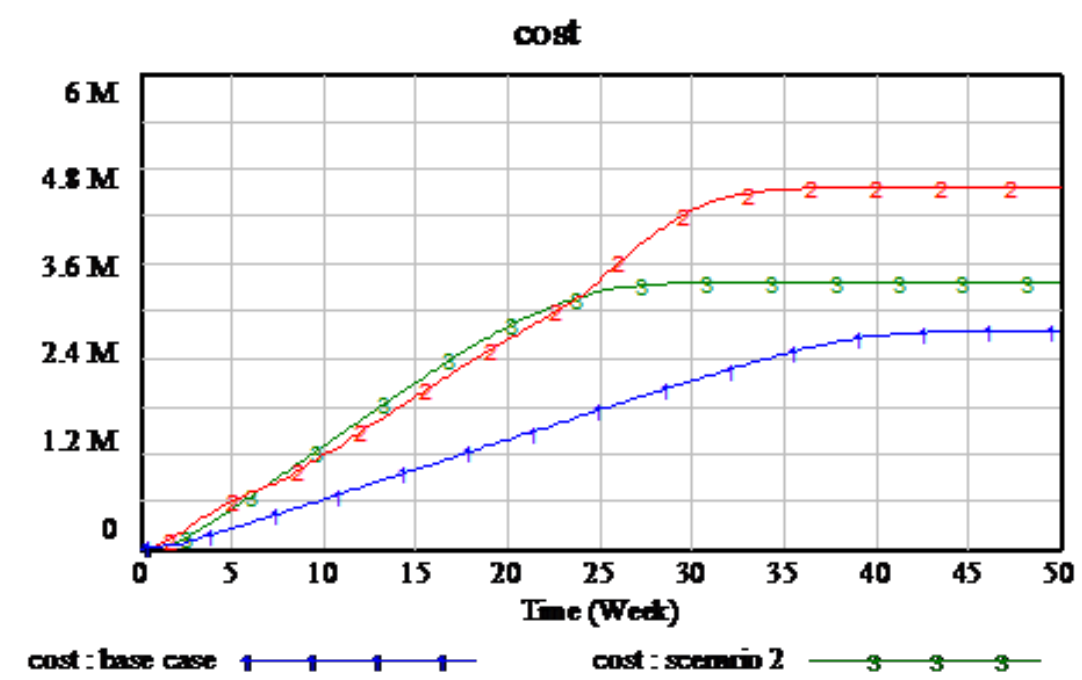

cost : scemio $1 \rightarrow z \quad z \quad z \quad z$

Fig. 6: Total cost of project 


\section{IV.II. Scenario 1}

According to client changes the design schedule changed to be 25 weeks. In this scenario, project manager has two options, either to increase work time by enabling the policy of increasing overtime for the same resource or to increase the number of designers. Starting with the first strategy, he will use overtime as a counter action to ensure that the schedule pressure will not cause failure to the project. Over time used ranged from one to two more added shifts to overcome the reduction of time. Unfortunately, the project exhibit schedule slippage. From figure (4), it can be seen that the Design work finished approximately (95\%)in 30 weeks with $20 \%$ delay in the schedule. In addition, using overtime increases rework by $9 \%$ compared with the base case as shown in Figure (5). Consequently, customer satisfaction decreases by $3 \%$. Also, total cost raised by $50 \%$ from its original value as shown in Figure (6). To sum up, the clear benefit of increasing overtime in the prevention of delays in time, over runs of cost, and satisfaction of customer could not be identified in this strategy. Furthermore, by the application of SI model, the PSI is $76.33 \%$, which mean it's critically decreased from the base case. That increases the risk of strategy failure i.e. leading to project failure.

\section{IV.III. Scenario 2}

In this section project manager will use the other strategy of hiring new qualified designers as a counter action to return back the project in order to finish the projectin the new required time ( 25 weeks).The expected number of experienced designersis doubled from the base case as in Figure (7). Interestingly, this duplication of resources may lead to a fake decision of duplication of cost. But, the overall response of the PSI is $92.5 \%$

Table 6: Cases results

Performance measure

Base case

$\begin{array}{lc}\text { Time } & 0.88880 \\ \text { Cost } & 0.99999 \\ \text { Quality } & 0.85000 \\ \text { customer satisfaction } & 0.80807 \\ \text { PSI } & 0.890893\end{array}$

PSI

0.890893 that means this strategy is good. The project exhibit good results, about $95 \%$ of work completed in 22 weeks with a $3 \%$ less rework than the base case. These results suggest thatusing more qualified designers will increase total cost by $15 \%$ compared with the base case as shown in Figure. (6),in addition, the customer satisfaction will increase by $8 \%$. To sum up the results of the three cases, it is tabulated in table (6). By comparing the results of the two strategies with the base case, it obvious that, the more the work will be done by the same resource in short time, the more the errors generated, consequently the more time required to correct these errors and the more cost will be paid. On the other hand, increasing experienced designers in the system lead to less cost than increasing working time of the same designer. That results in less work required from each experienced designer, hence less errors generated, which decreases the cost at the end. The final investigation of the results shows that PSI of strategy 2 is better than strategy one which mean that strategy two is better in overcoming the schedule compression

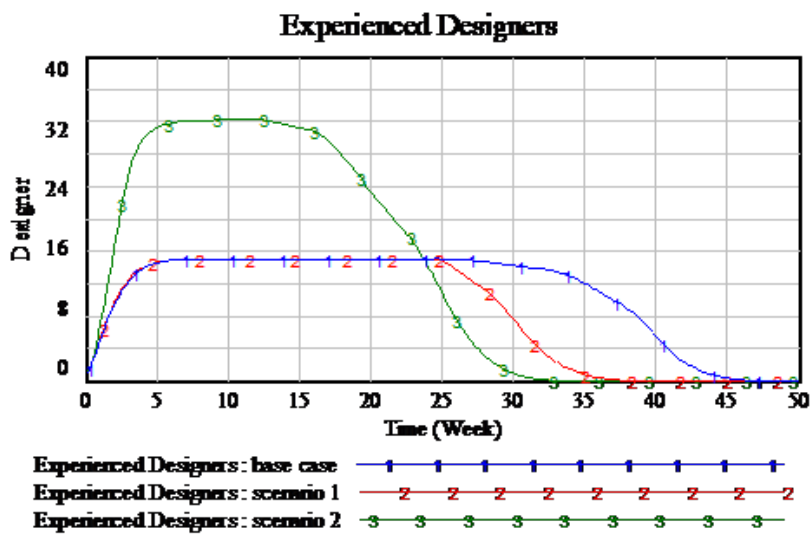

Fig. 7: Total number of designers

Percentage of the measure

$\begin{array}{cc}\text { Scenario 1 } & \text { Scenario 2 } \\ 0.80000 & 0.99999 \\ 0.65847 & 0.88809 \\ 0.82360 & 0.89969 \\ 0.77083 & 0.88415 \\ 0.763325 & 0.925061\end{array}$

\section{CONCLUSION AND FUTURE WORK}

Referring to the above mentioned challenges in the literature facing decision makers; makes it necessary forthem to have a dynamic tool to assessing the strategy and decisions taken. The purpose of the success measurement model for construction projects is presented in this paper, in addition, its value geminated by integrating it with the SD model. Overall, these results suggest that:

1. The much usage of overtime without a significant restwill cause fatigue to labors.Consequently, productivity will decrease dramatically. Hence, the system will suffer from reinforcing negative feedbacks of the generated errors. 
2. Closer inspections of results illustrate that strategy one lead to more rework.It increased by $30 \%$ greaterthan the base case.

3. Moreover it leads to slippage of schedule by $40 \%$ and the project cost increased by $40 \%$ more than the base case. 4. Finally, the negative significant result of this strategy is the low value of its index of success.

5. Further analysis of strategy two showed that hiring experienced designers, at early stage of assigning work will increase both productivity and quality.

6. The Strong evidence of this positive increase in quality is the reduction of rework, while inproductivity resulted in finishing work earlier that the planned time.

7. A positive correlation between customer satisfactionsand the above mentioned positive resultswill increase it by $8 \%$. 8. In addition, it makes the cost performance index decreased by $2 \%$.

9. All of these factors contribute in making this strategy index of success is 0.92 which is better than the other cases. Every model has some limitations which will be recommendations for future work.This dynamic model does not consider the two phases of design and construction. Integratingmore phases will generate an enhanced simulation to the real projects.In addition the rework cycle could be enhanced by considering multiple defects per task. Furthermore, researchers could test other scenarios to get the best of them. Finally the communication between designers could be considered and tested for its effect on rework and productivity.

\section{REFERENCES}

[1] B. Flyvbjerg, "What you should know about megaprojects and why: An overview," Project Management Journal, vol. 45, pp. 6-19, 2014.

[2] A. S. Faridi and S. M. El-Sayegh, "Significant factors causing delay in the UAE construction industry," Construction Management and Economics, vol. 24, pp. 1167-1176, 2006.

[3] X. Meng, "The effect of relationship management on project performance in construction," International journal of project management, vol. 30, pp. 188-198, 2012.

[4] A. M. Odeh and H. T. Battaineh, "Causes of construction delay: traditional contracts," International journal of project management, vol. 20, pp. 67-73, 2002.

[5] P. Boateng, et al., "A system dynamics approach to risks description in megaprojects development," Organization, Technology and Management in Construction: An International Journal, vol. 4, pp. 0-0, 2013.

[6] J. M. Lyneis and D. N. Ford, "System dynamics applied to project management: a survey, assessment, and directions for future research," System Dynamics Review, vol. 23, pp. 157-189, 2007

[7] S.-H. Ji, et al., "Policies for Improving Design-Build Delivery System in Korea."

[8] S. D. Lisse and P. P. Student, "System dynamics applied to outsourcing engineering services in design-build projects," Construction Management Association of America CM-eJournal, October, 2012.

[9] W. Li and Y. B. Moon, "Modeling and managing engineering changes in a complex product development process," The International Journal of Advanced Manufacturing Technology, vol. 63,pp. 863-874, 2012.

[10] J. Atkinson, et al., "RS 153-1 The Field Rework Index: Early Warning for Field Rework and Cost Growth," ed: Construction Industry Institute. Austin: CII, 2001.

[11] F. A. Mir and A. H. Pinnington, "Exploring the value of project management: linking project management performance and project success," International journal of project management, vol. 32, pp. 202 217, 2014.

[12] P. Patanakul and D. Milosevic, "The effectiveness in managing a group of multiple projects: Factors of influence and measurement criteria," International journal of project management, vol. 27, pp. 216-233, 2009.

[13] A. Sadeh, et al., "The role of contract type in the success of R and $\mathrm{D}$ defense projects under increasing uncertainty," Project Management Journal, pp. 14-22, 2000.

[14] E. Abd, et al., "Measuring Performance in Egyptian Construction Firms Applying Quality Management Systems," Journal of Construction Engineering and Project Management, vol. 1, pp. 18-27, 2011

[15] S. S. Hozien, et al., "HOW EGYPTIAN CONTRACTING COMPANIES TRANSLATE PROJECTS'QUALITY TO PROJECTS'PERFORMANCE," International Journal of Engineering Science and Technology, vol. 3, pp. 6008-6025, 2011.

[16] A. Elyamany, et al., "Performance evaluating model for construction companies: Egyptian case study," Journal of Construction Engineering and Management, vol. 133, pp. 574-581, 2007.

[17] A. R. Fayek, et al., "Measuring and classifying construction field rework: A pilot study," Research Rep.(May), 2003.

[18] G. Cserháti and L. Szabó, "The relationship between success criteria and success factors in organisational event projects," International journal of project management, vol. 32, pp. 613-624, 2014.

[19] A. Chan, "Framework for measuring success of construction projects," 2001

[20] A. Chen, "The relationship between procurment duration and designbuild success in transportation projects," 2009.

[21] N. Shariff, "Utilizing the Delphi survey approach: A review," J Nurs Care, vol. 4, p. 246, 2015.

[22] P. Love, et al., "Using systems dynamics to better understand change and rework in construction project management systems," International journal of project management, vol. 20, pp. 425-436, 2002.

[23] L. L. Rodrigues, et al., "System dynamics approach for change management in new product development," Management Research News, vol. 29, pp. 512-523, 2006.

[24] P. E. Love, et al., "Forensic project management: An exploratory examination of the causal behavior of design-induced rework," IEEE Transactions on Engineering Management, vol. 55, pp. 234-247, 2008. 